Tersedia Online di http://journal2.um.ac.id/index.php/jmsp/

ISSN Online : 2541-4429

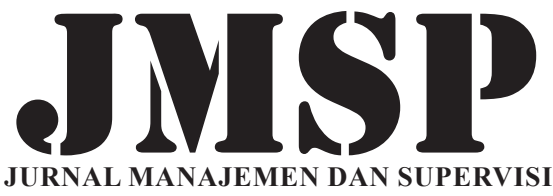

PENDIDIKAN

\title{
INTERNALISASI NILAI-NILAI RELIGIUS PADA KETERAMPILAN MANAJERIAL KEPALA SEKOLAH
}

\author{
Bagus Rachmad Saputra; Imron Arifin; Ahmad Yusuf Sobri \\ Manajemen Pendidikan Fakultas Ilmu Pendidikan Universitas Negeri Malang \\ Jalan Semarang 5 Malang Jawa Timur Indonesia \\ bagusrachmad47@gmail.com
}

\begin{abstract}
The purpose of this study was to determine (1) the process of internalizing religious values in the principals' conceptual skills, (2) the process of internalizing religious values in the technical skills of principals, and (3) the process of internalizing religious values in the interpersonal skills of principals at SDIT Baitul Izzah and SDI Plus Baitul Ikhlas Nganjuk. The approach used in this research is qualitative with a multi-site study approach. Data obtained through interviews with the principal as key informants, teachers, committees, and foundations. Data was collected from two sites in the form of structured and unstructured interviews, participatory observation, and document studies. Data sourced from field notes, documents, and interview transcripts that were reduced were then analyzed for validity and credibility tests using triangulation techniques. The results of the study include (1) internalization of religious values in the aspect of the principal's conceptual skills, (2) internalization of religious values in the technical aspects of the principal, (3) internalization of religious values in the interpersonal aspects of the principal's personal skills.
\end{abstract}

Keywords: internalization, religious values, managerial skills, principal

\begin{abstract}
Abstrak: Tujuan penelitian ini untuk mengetahui (1) proses internalisasi nilai-nilai religius dalam keterampilan konseptual kepala sekolah, (2) proses internalisasi nilai-nilai religius dalam keterampilan teknis kepala sekolah, dan (3) proses internalisasi nilai-nilai religius dalam keterampilan antar pribadi kepala sekolah di SDIT Baitul Izzah dan SDI Plus Baitul Ikhlas Nganjuk. Pendekatan yang digunakan dalam penelitian ini adalah kualitatif dengan pendekatan studi multi situs. Data diperoleh melalui wawancara dengan kepala sekolah selaku informan kunci, guru, komite, serta yayasan. Data dikumpulkan dari dua situs dalam bentuk wawancara terstruktur dan tidak terstruktur, observasi partisipatif, dan studi dokumen. Data bersumber pada catatan lapangan, dokumen, dan transkrip wawancara yang direduksi kemudian dianalisis uji validitas dan kredibilitas dengan teknik trianggulasi. Hasil penelitian antara lain (1) internalisasi nilai religius pada aspek keterampilan konseptual kepala sekolah, (2) internalisasi nilai religius pada aspek keterampilan teknis kepala sekolah, dan (3) internalisasi nilai religius pada aspek keterampilan antar pribadi kepala sekolah.
\end{abstract}

Kata Kunci: internalisasi, nilai-nilai religius, keterampilan manajerial, kepala sekolah

Sekolah berbasis agama terutama sekolah berbasis agama Islam cenderung diminati oleh masyarakat Indonesia. Minat terhadap sekolah berbasis agama Islam terutamadi wilayah perkotaan cukup tinggi. Branding sebagai sekolah formal yang memadukan pembelajaran umum dengan pendidikan agama menjadi daya tarik bagi masyarakat. Dikutip dari (RadarMalang.ID, 2018; Republika.co.id, 2010) dalam berita yang berjudul minat orang tua sekolahkan anak berbasis Islam tinggi. Menunjukkan bahwa ada tren minat masyarakat terhadap sekolah umum yang berbasis atau dipadukan dengan pendidikan nilainilai agama Islam.

Hal ini didukung oleh penelitian Ridho (2017) yang mengemukakan alasan atau minat orang tua dalam memilih sekolah berbasis agama Islam adalah berkualitas, unggul, memilih program pendidikan agama Islam yang baik, dan kedekatan dengan tempat tinggal. Sedangkan faktor lainnya adalah transportasi mudah, biaya yang terjangkau, status sekolah, dan lingkungan sekolah yang mendukung 
kreativitas peserta didik. Tentu membahas tentang tren minat masyarakat terhadap sekolah berbasis agama Islam perlu mengungkap faktor dibalik pengelolaan sekolah berbasis agama Islam itu sendiri.

Sebagaimana umumnya bahwa aktifitas pengelolaan sekolah tidak dapat dilepaskan dari keterampilan manajerial kepala sekolah dalam mengatur dan mendayagunakan segala sumber baik sumber daya manusia dan sumber daya non manusia. Keterampilan manajerial yang cakap menjadi kunci bagi kepala sekolah untuk membangun branding sekolah berbasis agama Islam (Indra, 2012). Kepala sekolah dituntut memiliki kecakapan sebagai seorang manajer yakni merencanakan dengan baik, mengorganisasikan, melaksanakan, dan melakukan pengawasan serta penilaian yang baik (Tyler \& Ed, 2016). Menurut (Yuk1, 1994) ada tiga inti keterampilan manajerial yang harus dimiliki dan dikuasai oleh kepala sekolah sebagai seorang manajer. Ketiga keterampilan tersebut adalah (1) keterampilan konseptual, (2) keterampilan teknis, dan (3) keterampilan dalam membangun hubungan sosial.

Ketiga keterampilan tersebut yang menjadi bekal bagi kepala sekolah untuk mengatur dengan baik aktifitas manajerial di sekolah. Pada sekolah berbasis agama Islam tentu aktifitas manajerial tidak dapat dilepaskan dengan nilai-nilai religius yang ada pada agama Islam (Aldosari, 2016). Tentu kepala sekolah harus mampu menginternalisasikan nialai-nilai religius yang terkandung dalam ajaran agama Islam untuk dipadukan dan diterapkan pada aktifitas pengelolaan sekolah (Susanto, 2007). Sebagai dasar dalam membangun branding sekolah umum yang dipadukan atau berbasis agama Islam. Menurut (Mahmud, 2017) internalisasi nilai-nilai religius yang diimplemntasikan oleh kepala sekolah dalam aktifitas manajerial di sekolah menekankan pada aspek kemampuan kepala sekolah membangun kompetensi akademis dengan kecakapan akhlak yang sesuai dengan ajaran agama Islam (Trianton, 2015).

Dampaknya bukan hanya terhadap peserta didik namun juga terhadap orang-orang yang terlibat langsung dalam aktifitas pengelolaan sekolah. Seperti pembiasaan nilai-nilai kejujuran, disiplin, sopan, santun, dan memiliki wawasan pengetahuan agama Islam yang mantap (Fatmawati, 2016). Nilai-nilai religius yang dibangun tersebut akan menjadi sebuah pembiasaan di lingkungan sekolah dan menciptakan iklim sekolah yang bernafaskan religius namun juga memiliki kemampuan yang baik bahkan diatas ratarata dalam aspek akademik (Busyairi, 2017; Mahmud, 2017; Ridho, Tinggi, Islam, \& Al, 2017). Seperti apa aktifitas kepala sekolah dalam mengatur sekolah umum berbasis agama Islam menjadi sekolah yang diminati masyarakat menjadi sebuah hal yang menarik untuk diteliti.

\section{METODE}

Penelitian ini menggunakan pendekatan kualitatif dengan rancangan studi multi situs. Studi multi situs adalah rancangan penelitian dengan melibatkan beberapa situs dan subyek penelitian sebagai kasus. Dimana peneliti langsung terjun ke lapangan untuk memperoleh data secara langsung di kedua situs yang sedang diteliti. Subyek penelitian diasumsikan memiliki karakteristik yang sama (Ulfatin, 2015). Data penelitian ini terdiri dari hasil pengumpulan data melalui kegiatan wawancara, hasil observasi partisipatif, dan studi dokumen. Disajikan dalam catatan lapangan, transkrip wawancara, dan dokumentasi.

Peneliti melakukan wawancara secara mendalam terkait dengan konteks yang sedang diteliti dengan kedua kepala sekolah di kedua situs. Kemudian peneliti melakukan wawancara dengan pihak lain di kedua situs untuk menguji dan memperoleh informasi yang valid dari kedua kepala sekolah dengan teknik bola salju. Dimana pihak-pihak yang ditentukan untuk wawancara memiliki hubungan secara personal maupun hubungan kerja dengan kedua kepala sekolah di kedua situs.

Peneliti melakukan pengamatan berperan serta di kedua situs untuk mengamati secara langsung dan merekam setiap peristiwa yang terjadi di kedua situs terkait dengan internalisasi nilai-nilai religius dalam keterampilan manajerial kepala sekolah. Peneliti melakukan pengamatan terhadap aktivitas pembelajaran dan kegiatan administratif di kedua situs tersebut.

Analisis data dilakukan dengan metode komparatif konstan dimana pengumpulan data dilakukan secara berulang-ulang dan kemudian dianalisis setelah pengumpulan data selesai melalui teknik trianggulasi sumber data dan teknik untuk memastikan keabsahan data di kedua situs. Tahap analisis 
data dilakukan dengan mengecek kredibilitas data yang diperoleh dengan mengecek data yang diperoleh dari sumber dengan teknik berbeda untuk menguji validitas data yang diperoleh. Data yang diperoleh juga diuji validitas dan keabsahannya pada beberapa sumber agar mendapatkan data yang benar-benar akurat, terpercaya, dan sesuai dengan fakta yang ada di lapangan.

\section{HASIL DAN PEMBAHASAN}

\section{Proses Internalisasi Nilai-Nilai Religius dalam Keterampilan Konseptual Kepala Sekolah}

Proses internalisasi nilai-nilai religius pada aspek keterampilan konseptual, di kedua situs, melakukan internalisasi nilai-nilai religius dalam penafsiran nilai-nilai positif yang terkandung dalam kitab suci Al-Qur'an dan hadist. Dimana konsep tentang manusia dari perspektif agama islam bahwa manusia lahir di muka bumi sebagai seorang pemimpin menjadi acuan kedua kepala sekolah dalam mengatur tata kelola manajerial di masing-masing sekolah (Mahmud, 2017). Selain itu aktivitas manajerial di sekolah merupakan konsep perpaduan, antara relugasi pendidikan secara umum yang dipadukan dengan kebijakan yayasan karena kedua sekolah merupakan sekolah swasta yang berada dalam naungan yayasan serta kebijakan yang merupakan keputusan bersama antara kepala sekolah dengan guru dan juga perwakilan komite sekolah (Arifin, I., Juharyanto, Mustiningsih, \& Taufiq, 2018). Triwiyanto, Suyanto, \& Prasojo (2019) menyatakan karena pentingnya faktor kepala sekolah ini, maka diperlukan figur dengan kapasitas memadai, kompetensi untuk mengelola hubungan sekolah dan masyarakat dalam rangka pencarian dukungan gagasan, sumber belajar, dan pembiayaan sekolah.

Konsep yang ditekankan dalam pengelolaan sekolah menekankan pada keberhasilan sekolah dalam mencapai prestasi yang ditentukan melalui pendekatan perspektif agama yang tidak dimiliki oleh sekolah lain (Kaelani, 2000). Di kedua sekolah tersebut juga terdapat perbedaan dalam aspek visi dan misi meskipun kedua sekolah memiliki latar belakang yang sama sebagai sekolah berbasis agama. Aspek yang ditekankan dalam keterampilan konseptual ini adalah bagaimana setiap pekerjaan merupakan amalan ibadah dijalan agama dan sebaik-baiknya adalah manusia yang mampu bermanfaat bagi orang lain (Hadi, 2016; Indra, 2012; Ridho et al., 2017). Perspektif agama itulah yang dilakukan oleh kedua kepala sekolah di masing-masing sekolah guna membangun identitas sekolah sebagai sekolah berbasis agama yang unggul secara intelektual dan unggul secara aqidah dan akhlakul karimah.

\section{Proses Internalisasi Nilai-Nilai Religius dalam Keterampilan Teknis}

Pada aspek keterampilan teknis, internalisasi yang dilakukan oleh kedua kepala sekolah memiliki kemiripan yakni sama-sama menekankan pada aspek spiritual, kedisplinan, kejujuran, dan suri tauladan dalam bekerja di sekolah. Dimana internalisasi tersebut dilakukan melalui program pembinaan baik pembinaan profesional guru maupun pembinaan pemahaman agama islam. Pembinaan profesional dilakukan berorientasi pada kemampuan guru dalam mengajar melalui kegiatan workshop dan seminar agar kemampuan guru dalam mengajar semakin baik (Wibawa, Troena, Armanu, \& Lumpkin, 2014).

Sedangkan pembinaan pada aspek spiritual atau pemahaman agama melalui pembinaan mengaji yang wajib diikuti oleh guru. Karena di kedua sekolah tersebut guru bukan hanya mengajar mata pelajaran umum namun juga harus mengajar mengaji kitab suci Al-Qur'an pada peserta didik. Program tilawah dan tahfidz menjadi tugas guru dalam membina peserta didik untuk menguasai kedua program pendidikan agama islam tersebut (Busyairi, 2017).

Kemudian kedua sekolah juga menerapakan tugas, pokok, dan fungsi melalui struktur organisasi sekolah yang memiliki job deskripsi yang jelas. Pendekatan lain dalam keterampilan teknis adalah pendekatan sebagai orang terdekat bagi guru dan pegawai sekolah lainnya (Arifin, Juharyanto, Mustiningsih, \& Taufiq, 2018; Daradjat, 2005). Dimana kepala sekolah di kedua sekolah tersebut menekankan bahwa pekerjaan harus dijalani dengan niat dan ibadah serta keikhlasan sehingga dalam mengajar peserta didik di kelas guru harus berkosentrasi penuh dalam mengajara dengan keikhlasan dan kesabaran sebagai bagian dari ibadah dan berjuang di jalan agama dalam mendidik generasi manusia yang cerdas dan berahklak mulia. Dimana melalui pendekatan tersebut dapat menjadi jalan bagi kedua kepala sekolah dalam menginternalisasikan nilai-nilai religius pada aspek keterampilan teknis yang 
harus dimiliki kepala sekolah sebagai seorang manajer (Mahmud, 2017; Ridho et al., 2017; Yusuf, 2008). Perspektif agama islam menjadi kunci kepala sekolah dalam melakukan tindakan-tindakan yang bersifat teknis dalam aktivitas pengelolaan sekolah di masing-masing sekolah yang dipimpin.

\section{Proses Internalisasi Nilai-Nilai Religius Dalam Keterampilan Antar Pribadi Kepala Sekolah}

Aspek keterampilan dalam membangun hubungan personal atau hubungan antar pribadi, nilai-nilai religius yang diinternalisasikan menekankan pada peran kepala sekolah sebagai pemimpin dan juga sebagai orangtua, sahabat, atau keluarga bagi guru dan pegawai yang ada di sekolah. Ketika memerankan peran sebagai pemimpin aspek religius yang ditekankan adalah kepala sekolah sebagai teladan bagi orang disekitarnya (Pasathang, Tesaputa, \& Sataphonwong, 2016; Purba \& Seniati, 2018). Maka secara pengetahuan, pemikiran, dan sikap kepala sekolah harus mencerminkan diri sebagai seseorang yang menjadi panutan di sekolah. Kepala sekolah membangun komunikasi yang aktif sebagai rekan kerja. Dimana guru dan pegawai sekolah selalu diminta untuk bekerja secara disiplin dan melaporkan setiap hasil pekerjaan yang dicapai termasuk kendala yang dihadapi guru apa saja guna dicari solusinya melalui musyawarah.

Sementara ketika memerankan peran sebagai orangtua atau keluarga bagi orang-orang disekitarnya. Kedua kepala sekolah melakukan pendekatan dengan berkunjung ke rumah guru dan melakukan kegiatan diskusi diluar sekolah untuk membangun komunikasi yang aktif dengan guru agar guru terbuka terhadap kepala sekolah dan agar tercipta hubungan yang harmonis antara kepala sekolah dengan orang-orang disekitarnya agar suasana kerja di sekolah kondusif. Melalui keterbukaan tersebut yang diharapkan oleh kedua kepala sekolah adalah sama dalam perspektif agama islam, sebaik-baiknya manusia adalah bermanfaat adalah manusia yang bermanfaat bagi orang lain (Saputra \& Imron, 2018) Dimana dengan sikap yang terbuka, guru akan jujur tentang permasalahan yang sedang dihadapi baik masalah pekerjaan maupun masalah pribadi dimana nantinya kepala sekolah dapat membantu dan memberi solusi dari permasalahan guru yang orientasi tetap kepada pencapaian pada tujuan sekolah yang telah ditetapkan bersama (Ridho et al., 2017; Saputra, B.R , Imron, A, 2018; Tchibozo, 2013).

\section{SIMPULAN DAN SARAN}

\section{Simpulan}

Berdasarkan hasil dan pembahasan di atas, simpulan dari penelitian ini adalah (1) internalisasi nilai-nilai religius terhadap kemampuan konseptual kepala sekolah merupakan proses pemikiran nilai-nilai agama yang berkaitan dengan pemikiran terhadap segala aktivitas pengelolaan sekolah yang memadukan antara nilai religius dengan konsep pengelolaan sekolah yang telah diatur pada kebijakan pendidikan secara umum serta penjabaran program-program sekolah yang berorientasi pada akademis dan keselarasan akhlak serta aqidah melalui kegiatan pembelajaran bernuansa keagamaan. (2) internalisasi nilai-nilai religius pada aspek teknis diwujudkan dalam bentuk pembinaan pserta didik dan guru pada kegiatan pembelajaran bernuansa religius dengan model terpadu. Kemudian integrasi antara kurikulum nasional dengan kurikulum sekolah yang berbasis keagamaan yang dimasukkan dalam RPP atau silabus guru. Pelibatan kerja sama dengan lembaga lain untuk meningkatkan kemampuan guru dan prestasi peserta didik baik di bidang akademis dan keagamaan. (3) internalisasi nilai religius pada aspek hubungan sosial dan kemanusiaan diimplementasikan melalui penanaman sikap jujur, disiplin, ikhlas, dan amanah seluruh warga sekolah. Peduli terhadap masyarakat di lingkungan sekitar sekolah melalui kegiatan santunan. Menjaga komunikasi yang aktif dan terbuka antara kepala sekolah dengan guru dan seluruh warga sekolah sebagai bagian dari keseimbangan antara hubungan manusia dengan Tuhan dan hubungan manusia dengan manusia. 


\section{Saran}

Berdasarkan simpulan diatas saran dari penulisan artikel ini adalah (1) kepada kepala sekolah internalisasi nilai-nilai religius harus terus dilakukan untuk membina guru, mengatur pengelolaan sekolah, dan membangun citra sekolah sebagai sekolah berbasis Islam dengan model terapdu. Meski pada akhirnya nanti akan terjadi pergantian kepala sekolah nilai-nilai religius yang telah ditanamkan hendaknya terus dijaga secara konsisten guna meningkatkan kualitas sekolah dalam upaya mencapai visi, misi, dan tujuan sekolah berbasis Islam terpadu. (2) kepada yayasan yang membina sekolah hendaknya juga terus memberikan dukungan dan masukan terhadap kepala sekolah seperti apa nilainilai religius dapat diinternalisasikan pada aktivitas pengelolaan sekolah dan aktivitas pembelajaran melalui pembinaan kepala sekolah yang baik.

\section{DAFTAR RUJUKAN}

Aldosari, dkk. (2016). Content Analysis of Science Book for Upper Primary Stage In Jordan and Intermediate Stage In Saudi Arabia From An Islamic Perspective: Analytical Comparative Study. Journal of Education and Practice, 7(7).

Arifin, I., Juharyanto, Mustiningsih, \& Taufiq, A. (2018). Islamic Crash Course as a Leadership Strategy of School Principals in Strengthening School Organizational Culture. SAGE Open, 8(3). https://doi.org/https://doi. org/10.1177/2158244018799849

Busyairi, M. (2017). Education Unit Tranformation for Maintain Its Existence In Islamic Boarding School Muti Case Study on Tebuireng Boarding School, Gading Islamic Boarding School, and Sidogiri Islamic Boarding School. Journal of Education and Practice, 8(7).

Daradjat, Z. (2005). Ilmu Jiwa Agama. Jakarta: Bulan Bintang.

Fatmawati, R. (2016). Internalisasi Nilai-Nilai Pendidikan Agama Islam Melalui Sistem Full Day School Anak Usia Dini Di TK IT Nurul Islam Yogyakarta. UIN Sunan Kalijaga Yogyakarta.

Hadi, J. P. (2016). Internalisasi Nilai Agama. UIN Malang.

I Made Artha Wibawa, Eka Afnan Troena, Armanu, NoermijatiLumpkin, A. (2014). The Role of Organizational Culture on Spiritual Leadership, Human Capital, and Employee Loyalty. European Journal of Business and Managemen, 6(21), 196-205. https://doi.org/https://doi.org/1 0.1080/00131725.2013.878420.

Indra. (2012). Internalisasi Nilai-Nilai Agama Islam Dalam Membentuk Siswa Berkarakter Mulia Di SMA Negeri 15 Binaan Nenggeri Antara Takengon Aceh Tengah. UIN Maulana Malik Ibrahim Malang.

Kaelani. (2000). Islam dan Aspek-Aspek Kemasyarakatan. Jakarta: Bumi Aksara.

Mahmud, M. (2017). Internalisasi Nilai-Nilai Karakter Dalam Meningkatkan Kompetensi Kepribadian Guru Di Sekolah Menengah Pertama Islam Terpadu (SMPIT) Al-Hidayah Sumenep. UIN Maulana Malik Ibrahim Malang.

Pasathang, S., Tesaputa, K., \& Sataphonwong, P. (2016). Teachers' Performance Motivation System in Thai Primary Schools. International Education Studies, 9(7), 119. https://doi.org/10.5539/ies.v9n7p119

Purba, D. E., \& Seniati, A. N. L. (2018). PENGARUH KEPRIBADIAN DAN KOMITMEN ORGANISASI TERHADAP ORGANIZATIONAL CITIZENZHIP BEHAVIOR. Makara Human Behavior Studies in Asia. https://doi.org/10.7454/mssh.v8i3.98

RadarMalang.ID. (2018). Minat Orang Tua Sekolahkan Anak Berbasis Islam Tinggi. 2 Februari 2018. Retrieved from https://radarmalang.jawapos.com/minat-orang-tua-sekolahkan-anak-berbasis-islam-tinggi/

Republika.co.id. (2010). Minat Masyarakat Atas Pendidikan Islam Meningkat. 2010. Retrieved from https://m. republika.co.id/minat-masyarakat-atas-pendidikan-islam-meningkat/

Ridho, A., Tinggi, S., Islam, A., \& Al, S. (2017). (Kajian Minat Masyarakat dan Prinsip Dasar Manajemen Lembaga Pendidikan Islam). 6, 655-677.

Saputra, B.R , Imron, A, \& J. (2018). Keterampilan Manajerial Kepala Sekolah Pada Sekolah Umum Berciri Khas Islam (Studi Kasus Di SDIT Ahmad Yani Kota Malang. Jurnal Manajemen Dan Supervisi Pendidikan, 2.

Susanto, E. (2007). MULTIKULTURALISME PENDIDIKAN AGAMA ISLAM (Telaah atas Pemikiran Nurcholish Madjid) Edi Susanto. Tadris, 2. 
Tchibozo, G. (2013). Cultural and Social Diversity and the Transition from Education to Work. Guy Tchibozo, Ed, 17. https://doi.org/https://doi. org/10.1007/978-94-007-5107-1

Trianton, T. (2015). Dalam Khazanah Budaya Cablaka. Ibda’. Jurnal Kebudayaan Islam, 11(2), 211-226.

Triwiyanto, T., Suyanto, Prasojo, L.D. (2019). The Thoughts of Ki Hadjar Dewantara and Their Implications for School Management in the Industrial Era 4.0. International Journal of Innovation, Creativity and Change, 5(4), 197-208.

Tyler, D. E., \& Ed, D. (2016). Communication behaviors of principals at high performing Title I elementary schools in Virginia: School leaders, communication, and transformative efforts. 2(2), 2-16.

Yukl, G. (1994). Leadership In Organizations. New Jersey: Prentice-Hall, Inc.

Yusuf, S. (2008). Psikologi Belajar Agama. Bandung: Maestro. 